\title{
Indonesian Food Processing Recipe Application as an Android-Based Learning Medium in Students of Culinary Study Program
}

\author{
Sulistiawikarsih ${ }^{1}$ Dian Agustina² Mawadda Azizah Sari Waruwu ${ }^{3}$ \\ ${ }^{1,2,3}$ Culinary Education Study Program, Bachelor Degree, Universitas Negeri Medan, Medan, Indonesia \\ *Corresponding author.Email: sulistiawikarsih57@gmail.com, Dianagustina@gmail.com, \\ mawaddaassw@gmail.com
}

\begin{abstract}
The development of technology affects the role of an android itself. Nowadays, all activities can be done with android. One of the obstacles in learning Indonesian food processing is the determination of raw recipes to be practiced. Based on this condition, the researchers made an application recipe book Indonesian food processing in students based on android. The research process is conducted based on Fish Bone Diagram, Testing method is Blackbox Testing method. The testing phase of the app focuses only on the functionality of the app. Based on the conclusions, it is known from this study to produce a responsive online application-based food recipe application, so that it can be accessed by users wherever they are while still connected to the internet, provide better information than similar services, and make it easier for users to determine the menu of food recipes to be practiced.
\end{abstract}

Keywords: Indonesian Food Processing Recipes, Applications.

\section{INTRODUCTION}

The rapid development of technology affects the role of an android itself. In this day and age, almost all activities can be done with android. Every time people can see the development of technology from day to day and the technology can be used as a human tool to complete some activities as quickly and precisely as possible. Almost all circles can use android both from the bottom to the upper class, especially in the field of education.

In the world of education, android can be used as a medium to deliver lesson materials to students, namely to be props or learning media. As a media tutorial, android has advantages in terms of interaction, fostering selflearning interests and can be adapted to the needs. One of the lecture materials taught to Tata Boga students as a prerequisite for obtaining a bachelor's degree is to graduate in the Indonesian Food Processing course. Indonesian Food Processing course is one of the practical courses that contains about processed materials throughout Indonesian food from sabang to merauke, with priority recipes native to the region itself.
One of the obstacles in learning Indonesian food processing at this time is the determination of raw recipes, which are to be practiced, because basically students will be instructed regional food to be processed and then students will look for recipes from various sources of reference. In this recipe search process, students will submit several recipes obtained from many sources so that educators will have difficulty choosing the right recipe where the number of recipes submitted is currently undergoing modifications or changes in the shape and taste of both the ingredients and the look of the food itself.

Android provides an open platform for developers to create their own apps for use by a variety of mobile devices. Android has various advantages as a software that uses an android codebase that can be distributed openly (open source) so that users can create new applications in it. In this case, it is mandatory for students to access electronic learning resources. Although it is optional, students who utilize it will certainly have additional knowledge or insight, complementary (complement) that is if electronic learning resources are programmed to complement the learning resources received by students in the classroom (Lewis, 2002). The issue that will be raised in this paper is how to create an 
Android-based multimedia application that discusses traditional Indonesian food recipes.

In this scientific writing the author imposes limits on problems related to the application of traditional food recipe learning systems that exist throughout Indonesia by taking the example of one recipe. The purpose of this study is to produce an application of Indonesian food processing recipes that are useful to help users in determining recipes that are in accordance with standards and standards, so as to help users in practice courses.

\section{LIBRARY REVIEW}

\subsection{Definition of Application System}

A system is a collection of components that are interconnected with each other forming a unity to achieve a certain goal. (Jogiyanto: 2009) A system is a group of two or more interconnected components or subsystems that function with the same purpose. (Hall, James A: 2007).

\subsection{Recipes}

Recipes are a set of cooking rules consisting of the necessary ingredients, how to make, the dosage of ingredients and other supporting information such as the number of servings, the time of manufacture, and the level of difficulty. The number of servings needed by each person is different, so it is necessary to calculate the appropriate amount of material.

\subsection{Android}

Android is an operating system for linux-based mobile devices that includes an operating system, middleware, and applications. Android is an open source operating system that is free to be distributed and used by any vendor.

\subsection{Indonesian Food Processing}

Indonesian Food Processing courses are courses that must be taken by every student in the field of gastronomy, in the eyes of this course learn a variety of knowledge and skills in the field of food.

\subsection{Learning Media}

The term media is very popular in the field of communication, the teaching and learning process is basically also a process of communication, so the media used in learning is called learning media.

\section{RESULTS AND DISCUSSION}

\subsection{Research Design}

To design this android-based Indonesian food recipes application, researcher conducted a library study to obtain research-related data from various reading sources such as Indonesian food processing diktat books, application creation manuals using programming languages, journals and reference books on Indonesian food recipes.

\subsubsection{Design}

At the design stage, system workflow design and database design are done based on user story that has been created before.

\subsubsection{Coding}

Coding is the stage of creating a system based on the design that has been created. In the creation of this system is done by two people, namely a programmer and a tester This stage can be done repeatedly (refactoring) if there is a correction.

\subsubsection{Testing}

Testing is the testing stage of the system, every recipe that is being developed will first undergo testing. If it is still not in accordance with the request, it will be corrected on the corrected part. If it is in accordance with the request then the system can already be implemented.

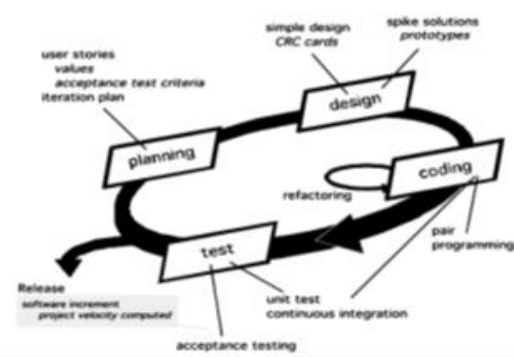

Figure 1. Application Program Stages

\subsection{Application Design}

The app created by researchers uses almost every page with a picture background. In this case it aims to make the application made more interesting. The previously created background has gone through the design process using Adobe Photoshop's graphics processing program. The application is created with the help of wixapp program. This application in addition to making it easier to design programs in the form of multimedia, the final results of the program can be compiled into Android apk or website.

\subsection{App Page View}

On the home screen of the application will be seen background application with menu button in the far right corner. The initial view of the application contains several menus namely Home menu, Recipes, About Application.

The page view of Traditional Indonesian Food Recipes Application is as follows:

1. Initial view, this page displays the initial view when the application program is run. 


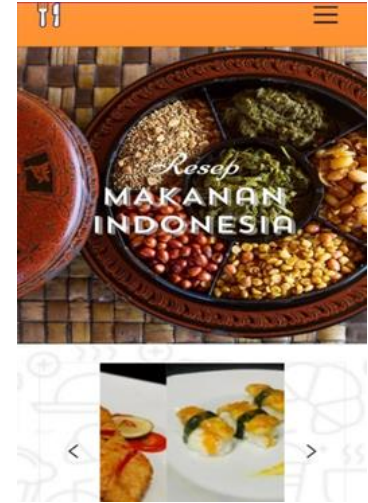

Figure 2. Home View

2. Menu View, Used to run the selected application.
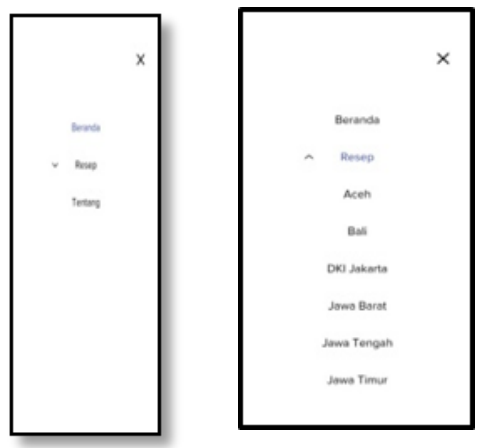

Figure 3. Home View

3. Recipes, Displaying recipes from an area

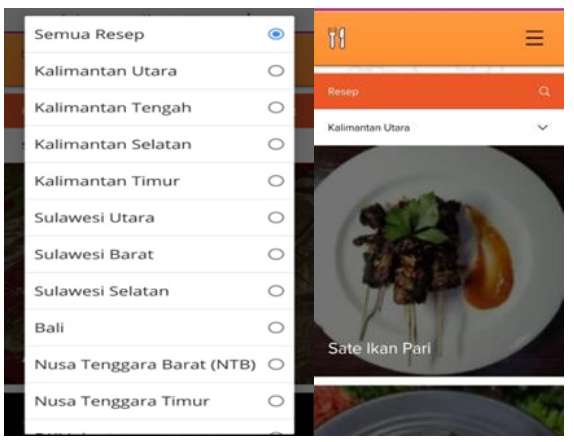

Figure 4. Recipe Menu View

4. About, Introduction of an application along with the author of the application.

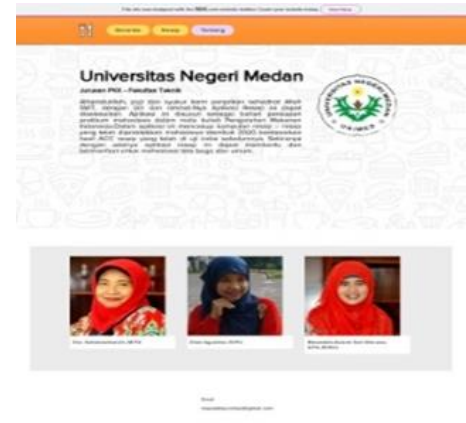

Figure 5. End View

\subsection{App Trial}

The next stage is conducted testing of the application program by researchers. This test is intended to evaluate the application of food recipes that have been made can run well. The testing phase of the app focuses only on the functionality of the app. See if the app is as expected.

\subsubsection{Validation Testing}

Validation testing is used in validating the needs 1 is to the implementation of the system created. This test will be tested using inputs given to a function where the input will provide output results. This cooking recipe application validation test tested 31 functional needs as well as alternative flows. Validation tests performed on cooking recipe applications are $100 \%$ valid.

\subsubsection{Application Testing}

Application Testing aims to see the functionality of the source code application is correct or there are still errors. Methods tested in this test include questionnaire methods. In the test this application sees if the application is in accordance with the expected. Unknown on the right ma recipe application obtain valid results.

\section{CONCLUSION}

Based on the results of the description, it can be drawn to the conclusion as follows; design this Indonesian Food Recipes application using the WIxsite program by making the application faster. And Indonesian Food Recipes application based on Android is the main alternative choice for students for practice ingredients.

There are suggestions in the development of this application are as follows; in this application is expected to be operated on various types of Operating System (OS) based on mobile or tablet and types of food in the application of Indonesian Food Recipes can be developed by adding types of snacks, traditional cakes and beverages typical of the region in Indonesia.

\section{REFERENCES}

[1] Hall, James A. 2007. Accounting Information System. Jakarta: Salemba Four.

[2] HM, Jogiyanto. 2009. Information Technology Systems. Yogyakarta: Andi.

[3] Klenova, D. (2010) The Language of Cookbooks and Recipes. Masaryk University

[4] Kuncoro, S., Sari, M. W. and Wibawa (2017) 'Design a Mobile Web-Based Central Java Recipe Application', pp. 278-28 
[5] Lestari, S. Y. and Kusrini (2012) 'Building a Mobile Application of Asian Cuisine Recipes (Indonesia, China, Japan) Based on Android', Dasi Journal, 13, pp. 36-41

[6] Lewis, Diane E. 2002. "A Departure from Training by the Book, More Companies Seing Benefit of E Learning", The Boston Globe, Globe Staff (Internet source: http://bostonworks.boston.com/globe/art icles/052602/elearn.html)

[7] Santoso, T. A. (2016) 'Mobile Web Based Cooking Recipe Search Application Based on Availability of Ingredients With Simple Additive Weighting Method

[8] Yusuf Hadi Miarso, Seedling of Educational Technology, Jakarta: Kencana, 2007 